\title{
A Parylene temporary packaging technique for MEMS wafer handling
}

\author{
L. Wen ${ }^{\mathrm{a}, *}$, K. Wouters ${ }^{\mathrm{a}}$, F. Ceyssens ${ }^{\mathrm{a}}$, A. Witvrouw ${ }^{\mathrm{b}}$, R. Puers ${ }^{\mathrm{a}}$ \\ a ESAT-MICAS, Katholieke Universiteit Leuven, Leuven B-3001, Belgium \\ b Imec, Kapeldreef 75, Leuven B-3001, Belgium
}

\section{A R T I C L E I N F O}

\section{Article history:}

Received 13 October 2011

Received in revised form 31 March 2012

Accepted 31 March 2012

Available online $\mathrm{xxx}$

\section{Keywords:}

Parylene

Temporary packaging

MEMS

Wafer handling

\begin{abstract}
A B S T R A C T
This paper presents a wafer-level temporary packaging technique utilizing a chemical vapor deposited (CVD) poly-(p-xylylene) polymer Parylene film, and oxygen plasma etching. As a test case, released, unpackaged accelerometers fabricated in a SiGe MEMS above IC technology were coated with two different types of Parylene, Parylene $\mathrm{N}$ and Parylene $\mathrm{C}$ respectively, as dicing protection. Oxygen plasma is used to etch the Parylene and to release the freestanding structures after dicing. The final releasing results are compared, and Parylene $\mathrm{N}$ turns out to be the best material for temporary packaging. The devices are electrostatically characterized after the Parylene coating. The results demonstrate the feasibility of using Parylene as a temporary protective material for both metal and semiconductor MEMS devices, to prevent any damage during subsequent wafer handling and dicing.
\end{abstract}

(C) 2012 Elsevier B.V. All rights reserved.

\section{Introduction}

Wafer level packaging is an important technique and process for MEMS (micro electro mechanical systems), since it has an enormous impact on the cost, yield and reliability [1-4]. Wafer level packaging (0-level packaging) normally refers to the process of packaging a wafer prior to dicing. The technique can be categorized into permanent wafer level packaging and temporary wafer level packaging respectively. The permanent wafer level packaging can protect the MEMS devices from mechanical damages and contaminations during the fabrication process, such as wafer dicing and wafer handling. It can also provide the cavity (including vacuum condition, if needed) and electrical interconnections required for the MEMS' operation. To achieve the permanent packaging, various methods can be implemented, including anodic bonding [5-10], and bonding with an intermediate eutectic bonding in case of chip capping [11-20] and deposition sealing in case of thin film capping [21]. Permanent packaging has many advantages, such as protecting of the MEMS structures during the plastic molding of the devices.

Temporary wafer level packaging, on the other hand, can also protect the MEMS devices from mechanical damages and contaminations during the typical, sometimes harsh, wafer manipulations. In this case, the package will not be used during plastic molding or another first level packaging process as it is not really intended to last. So it does not fulfill the final packaging requirements (for example transparency in the case of optical MEMS).

\footnotetext{
* Corresponding author. Tel.: +32 16 321716; fax: +32 16321975.

E-mail addresses: lwen@esat.kuleuven.be, wenlianggong@aol.com (L. Wen).
}

In some applications, however, temporary wafer level packaging is preferred. For example, an optical MEMS might need a special optical window in its final first level package, which cannot be processed on the wafer level as the window thickness is too thick or no good bonding technique exists which can bond the window material to the MEMS wafer. A temporary packaging technique can then be used to protect the optical MEMS structures during wafer handling, electrical tests, dicing and gluing the chip into the final package including making the wire bonding to the final package [22]. If the MEMS device cannot be tested on a wafer, and a permanent package is not required, temporary wafer level packaging is an interesting alternative. Several temporary packaging methods have been proposed in literature, including thermo-compressive packaging [23], the use of glass caps laminated with UV-sensitive tape [24], or a heat-decomposable bonding ring [25]. These temporary packaging processes involve some challenges, such as the alignment of the capping to the MEMS devices, the debris-free stripping process to decap the package from the devices after the dicing step, etc. This additional processing can result in a lower yield of the final device, hence in an increase the fabrication cost. As an example, we discuss the latter challenge: to achieve a debris-free stripping process, the ability to handle small encapsulated die is required. During the stripping procedure, no damage can occur to the MEMS devices. However, both the thermal and mechanical conditions required by the decapping process, as well as the debris of the bonding materials on the decapped devices risk to jeopardize its functionality. Another option is to use polymer materials as a protective layer during handling, followed by a plasma etching technique for final release. A study has been carried out to obtain the etch characteristics of thick polynorbornene films used for electronic packaging applications [26]. $\mathrm{O}_{2}$ and $\mathrm{CHF}_{3}$ plasmas have been 
(a)

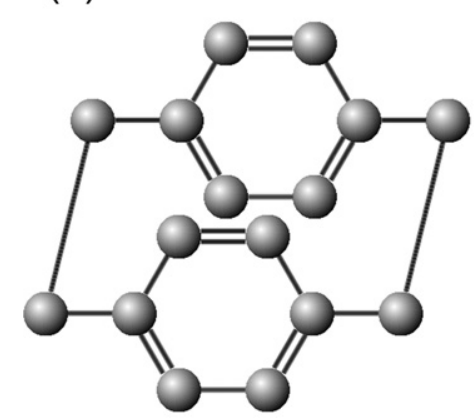

(b)

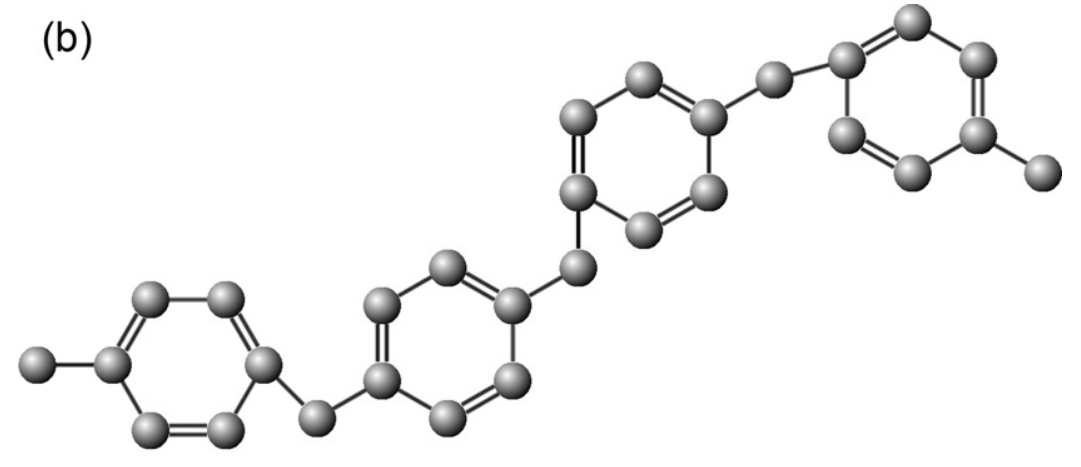

(c)

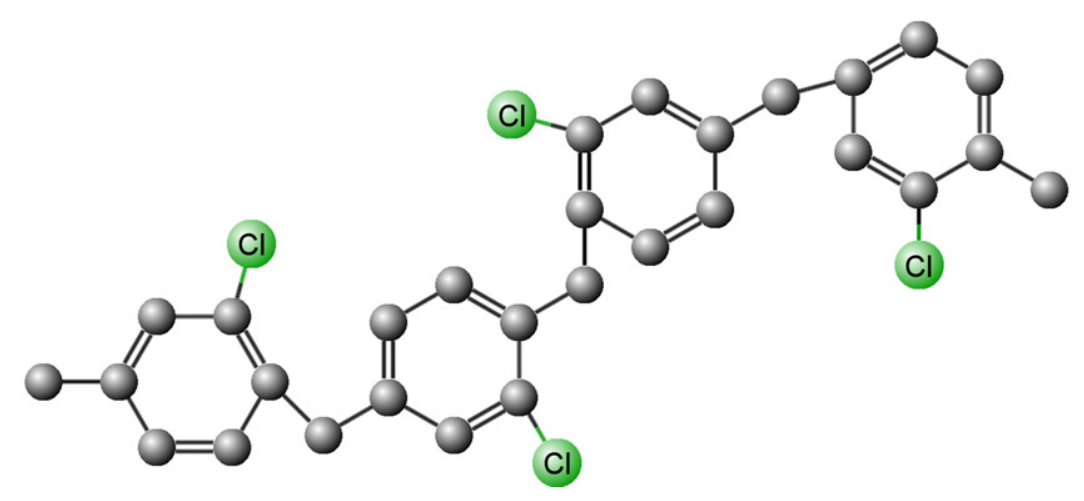

Fig. 1. The chemical structure of the Parylene dimer: [2.2]paracyclophane (a), Parylene N (b) and Parylene C (c).

studied. Two polynorbornene materials were investigated in this study: one with an epoxy substituent and the other with a silicon substituent.

In this paper, we report a novel alternative temporary packaging method, by using a CVD deposited Parylene layer as the packaging material for MEMS. The low temperature CVD process of the Parylene material can ensure the overall coverage of each surface of the free-standing structure. The MEMS device can thus be protected on the wafer during subsequent harsh manipulations in the processing line. As the packaging is only temporary, a clean releasing process needs to be foreseen. Oxygen plasma etching is used to strip the Parylene layer thoroughly. A device with comb fingers is used to demonstrate the technology. Two different varieties of the Parylene materials will be compared for this temporary packaging. The demonstration device is characterized electrostatically, and the results are discussed and compared with FEA (finite element analysis) simulations. The merits of the proposed method lay in the fact that no alignment procedure is required for the packaging, and that a debris-free process can be achieved. Moreover, it has the advantage of batch fabrication compatibility.

\section{Experimental details}

\subsection{Parylene deposition}

Parylene is the trade name of a variety of chemical vapor deposited poly(p-xylylene) polymers, used normally as moisture and dielectric barriers. Parylene chemistry is considered as a green polymer chemistry, which features self-initiation, un-termination, and does not require any solvent or catalyst. The commonly used precursor (commonly known as the dimer), [2.2]paracyclophane (Fig. 1(a)), yields 100\% monomers upon heating [27]. The two commonly used derivatives of the Parylene polymers are Parylene $\mathrm{N}$ (Fig. 1(b)), and Parylene C (Fig. 1(c)).
The deposition process of the Parylene polymers is illustrated in Fig. 2. In Stage 1, the dimer powder is carefully weighed and transferred into the vaporizer chamber. There the dimer is heated up above $125^{\circ} \mathrm{C}$ under a pressure of 3.5 Pa. The evaporated dimer then enters the pyrolysis furnace chamber (Stage 2 ), where the [2.2]paracyclophane cracks to the p-exlylene intermediate, commonly known as the Parylene monomer. This happens under the condition of high temperature (above $660^{\circ} \mathrm{C}$ ) and low pressure (3.5 Pa). For different Parylene derivatives, these conditions can vary slightly. For example, for the fluorinated Parylene, the pyrolysis temperature is generally $700{ }^{\circ} \mathrm{C}$, higher than that of the dimer of Parylene $C$, simply because the $-\mathrm{CF}_{2}-\mathrm{CF}_{2}$ bonds on the octafluoro[2.2] paracyclophane is stronger than the $-\mathrm{CH}_{2}-\mathrm{CH}_{2}$ bonds on the [2.2]paracyclophane. After the pyrolysis stage, the generated monomer is transferred into the polymerization chamber (Stage 3 ), where the chemical vapor deposition (CVD) will occur. The deposition of the Parylene includes two steps: physisorption and polymerization. The process is a function of deposition chamber pressure and temperature. There is a threshold temperature for Parylene materials, above which no polymerization will be observed. Once the sample temperature drops below the threshold temperature, the p-xylylene intermediate will polymerize [28]. The advantage of this process is that the deposition will be isotropic. The entire exposed surface of the device will be coated conformally, if the surface temperature is unique. The sample temperature is controlled and monitored by two temperature sensors on the wall of the polymerization chamber. Since we keep the chamber pressure constant for each experiment, the temperature of these two temperature sensors will be the major parameters that govern the final deposition rate. After Stage 3, the excessive amount of the monomer will be transferred into the cold trap, where the temperature is preset to be $-90^{\circ} \mathrm{C}$.

In this paper, two types of Parylene are studied: Parylene $C$ (having one chlorine group per repeat unit) and Parylene N. The threshold temperatures of the Parylene $\mathrm{C}$ and Parylene $\mathrm{N}$ are 


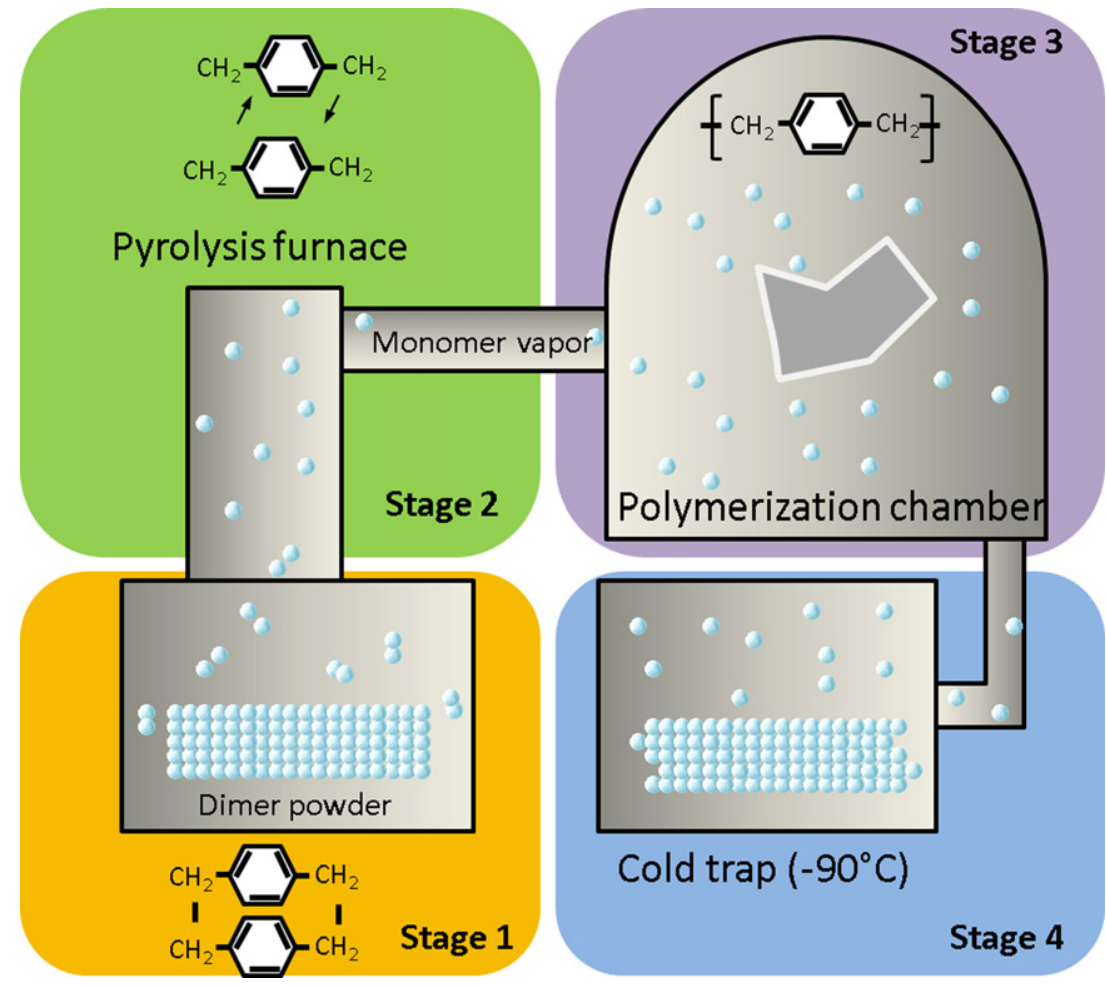

Fig. 2. Schematic illustration of the Parylene CVD coating principle of Parylene N.

$90^{\circ} \mathrm{C}$ and $40^{\circ} \mathrm{C}$ respectively. The higher threshold temperature of Parylene $C$ is because of the larger molecular weight due to the additional chlorine group. Since the deposition rate is a function of the chamber temperature, the higher threshold temperature will lead to a faster deposition speed [29]. For the deposition speed reason, Parylene $C$ will be investigated first as the temporary packaging material candidate. Then the Parylene $\mathrm{N}$ will be investigated and the results will be compared between these two Parylene derivatives.

\subsection{Test device packaging}

The demonstration device used in this work is an in-plane SiGe capacitive accelerometer structure, with $110 \mu \mathrm{m}$ long comb shaped fingers and a $3 \mu \mathrm{m}$ free-standing gap underneath the structure. The distance between the adjacent fingers is $1 \mu \mathrm{m}$ and the smallest feature gap is $500 \mathrm{~nm}$. The device has a large seismic mass surface compared ( $100 \mu \mathrm{m}$ in width) to the comb features ( $2 \mu \mathrm{m}$ in width) and the suspension spring features ( $2.5 \mu \mathrm{m}$ in width). The basic functioning unit of the device is the sensing comb finger unit, including one moving finger on the seismic mass and two sensing fingers on both sides of the rotor finger. If a DC voltage is applied to the moving finger and one of the sensing fingers, the device will respond due to the electrostatic force. The testing devices use $\mathrm{SiO}_{x}$ as the sacrificial layer. To prepare for the Parylene temporary packaging test, the test devices are first released with the BHF solution for $65 \mathrm{~min}$, followed by the critical point drying (CPD) process, to obtain a free-standing MEMS structure (Fig. 3). The released devices are screened by the electrostatic probe tests prior to the Parylene coating to pick out the best functioning devices.

Fig. 4 illustrates the coating process of the proposed Parylene temporary packaging technique. The released test device is first covered with Parylene by using the described CVD process. Thereafter, the coated device can be handled or diced with common cleanroom equipments. After that, the finished dies are placed in
Table 1

The CVD coating conditions of the Parylene C and the Parylene N.

\begin{tabular}{lllll}
\hline $\begin{array}{l}\text { Parylene } \\
\text { type }\end{array}$ & $\begin{array}{l}\text { Dimer evaporation } \\
\text { step } 1\end{array}$ & $\begin{array}{l}\text { Dimer evaporation } \\
\text { step } 2\end{array}$ & $\begin{array}{l}\text { Temp. } \\
\text { monomer }\end{array}$ & $\begin{array}{l}\text { Temp. } \\
\text { chamber }\end{array}$ \\
\hline $\mathrm{C}$ & $130^{\circ} \mathrm{C} 1 \mathrm{~h}$ & $135^{\circ} \mathrm{C} 1 / 2 \mathrm{~h}$ & $720^{\circ} \mathrm{C}$ & $130^{\circ} \mathrm{C}$ \\
$\mathrm{N}$ & $125^{\circ} \mathrm{C} 1 \mathrm{~h}$ & $130^{\circ} \mathrm{C} 1 / 2 \mathrm{~h}$ & $660^{\circ} \mathrm{C}$ & $80^{\circ} \mathrm{C}$ \\
\hline
\end{tabular}

the plasma etcher to release the free-standing structures by a Parylene etch. The final process should result in a functioning device again after the plasma release.

The test devices are coated with Parylene $\mathrm{C}$ and Parylene $\mathrm{N}$ respectively as described in Table 1 . The CVD tool used in this work is the PPCS type PP220 plasma Parylene coating system. The deposited Parylene layer is conformal on the entire free surface of

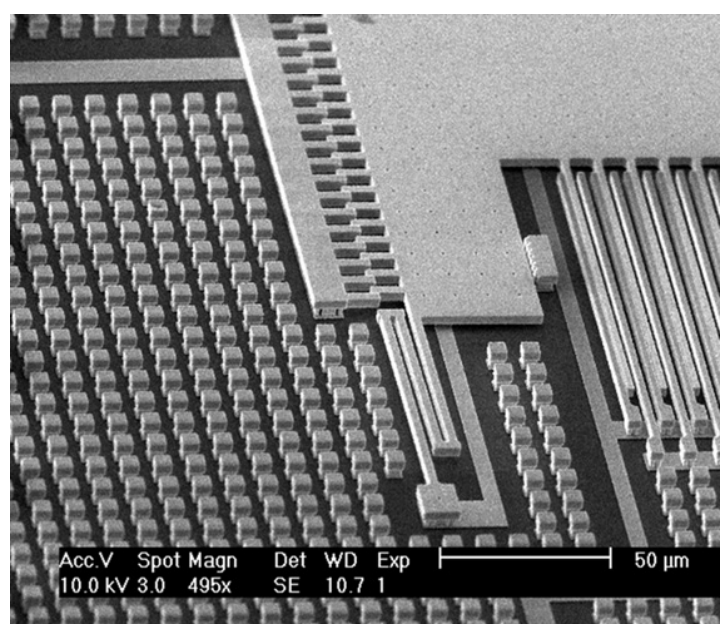

Fig. 3. SEM view of the SiGe MEMS inertial sensor structure before the Parylene coating. 

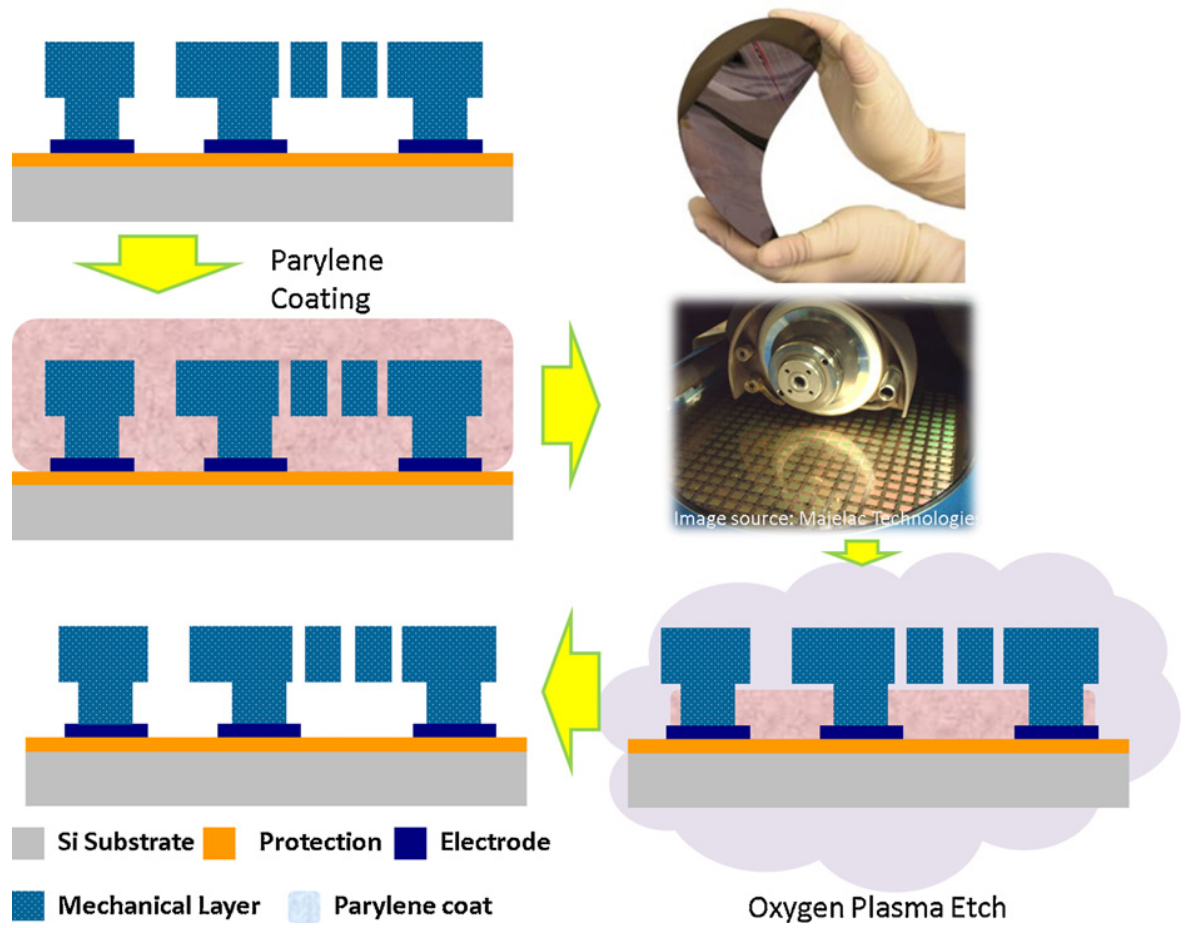

Oxygen Plasma Etch

Fig. 4. Schematic of the proposed Parylene temporary packaging process.

the test device. Fig. 5(a) is a tilted SEM (scanning electron microscope) view, showing the test device after the Parylene coating process. This top view shows the test device is well covered by the temporary packaging material, all the lateral intervals and gaps between any moving parts are sealed. Fig. 5(b) is the SEM view of the cross section of a finger beam through a FIB (focused ion beam) milled opening. A destructive test was carried out to inspect the cross section after deposition. The finger beam is cut by the FIB vertically, and two adjacent beams' cross sections can be seen. Since the SiGe process includes four deposition steps for the structural layer, the interface between these deposition steps can be partially observed. The material around the finger beam is deposited Parylene. This view shows that the Parylene coating covers not only the top surface but also the side wall and the bottom surface of each comb finger, as expected. For Parylene $\mathrm{N}$ and Parylene $\mathrm{C}$ respectively, the thicknesses of the Parylene layers after the coating processes are different, under the mentioned coating conditions. The difference of the two Parylene coatings is due to the difference of the threshold temperatures. The average thicknesses are: $2.4 \mu \mathrm{m}$ for $6.5 \mathrm{~g}$ of Parylene $\mathrm{C}$ dimer powder, and $2 \mu \mathrm{m}$ for $7 \mathrm{~g}$ of Parylene $\mathrm{N}$ dimer powder. This protective Parylene layer should protect the freestanding parts from capillary attraction and dicing debris during wafer dicing and handling. To prove the protection ability, after the deposition process, the samples are treated in an ultrasonic water bath for $10 \mathrm{~min}$, to simulate the environment harsher than that of the wafer handling or water assist laser dicing process [30]. No visible damage could be observed at this stage, indicating a solid fixation of the MEMS' vulnerable structures.

\subsection{Saw dicing tests}

A dicing test has been performed to illustrate the protection capability of this Parylene temporary package against a standard wafer dicing process. A Disco DAD 321 saw dicer is used for this purpose. The width of the dicing line is chosen to be $90 \mu \mathrm{m}$. The dicing tests are conducted on two comparative samples. One sample

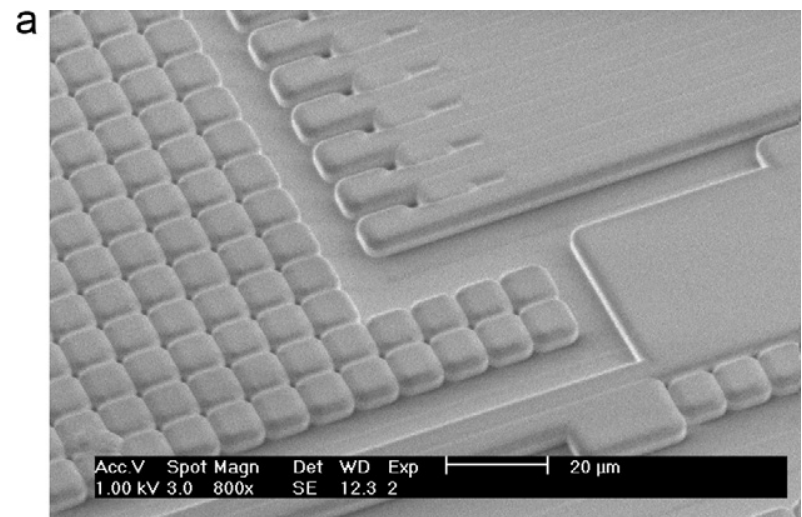

b

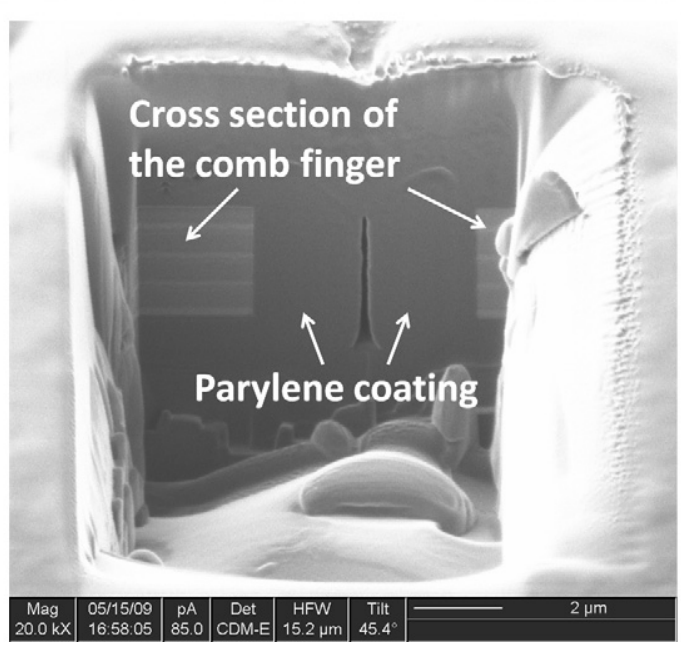

Fig. 5. (a) SEM view of the Parylene coated test device and (b) cross section view of the Parylene covered finger beam through a focus ion beam milled cavity. 


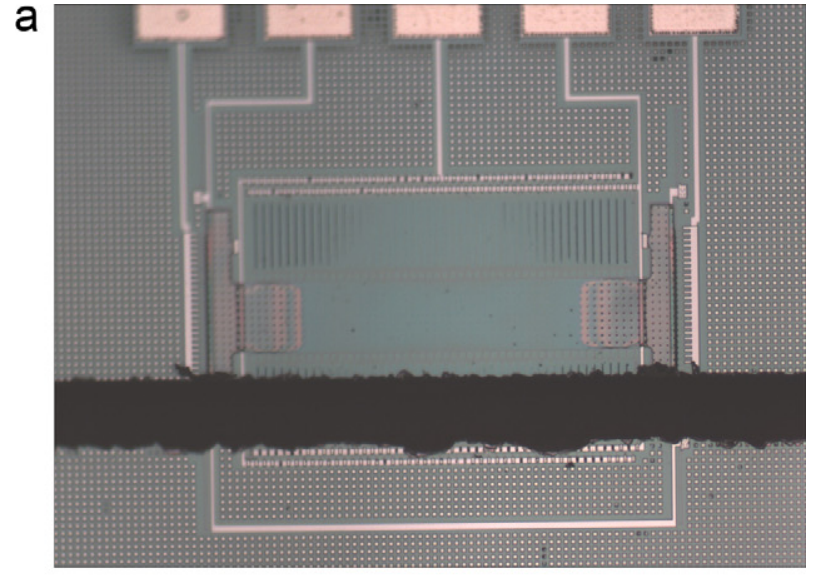

b

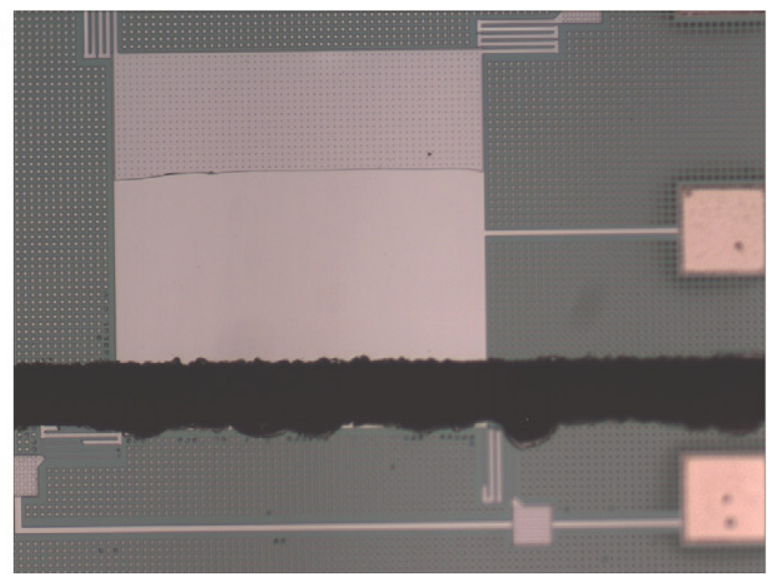

C

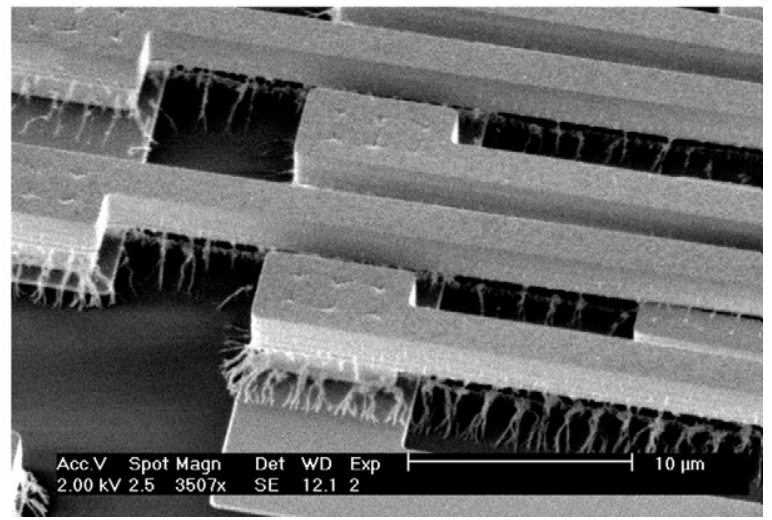

Fig. 6. (a) Optical image of the destructive dicing test on (a) a comb drive shaped device without Parylene coating and (b) a plate shaped device without Parylene coating.

contains released free-standing MEMS devices with the Parylene temporary package, while the reference sample contains similar devices without the Parylene wafer level package. Each sample consists in an array of 12 individual devices. The dicing lines were planned either directly through MEMS devices for an aggressive test, or on the normal scribe lines alongside the devices.

In Fig. 6(a) and (b) show respectively a comb drive shaped device and a plate shaped device being diced through. These are devices without Parylene wafer level package protection. With the dicing line right through the device, the destructive effect of the dicing wheel can clearly be observed from the optical pictures. For the comb drive device, the complete proof mass with all combs is destroyed, only leaving some debris at the original position of the free standing structure. Also, for the plate shaped device, a large a

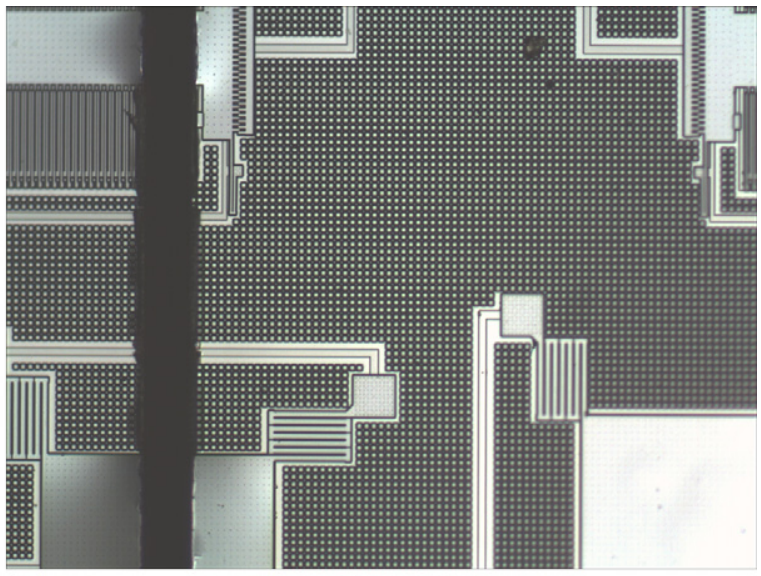

b

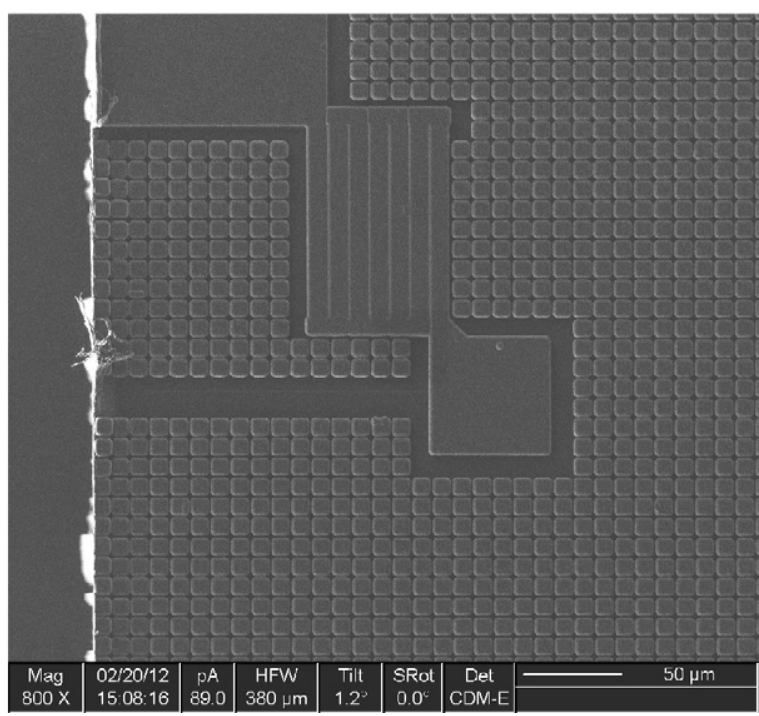

Fig. 7. (a) Optical image of the destructive dicing test through devices with Parylene protection and (b) SEM view of the diced device with Parylene coating, the MEMS structure is well protected against the dicing.

portion of the free standing structure disappeared. This result is to be compared to the dicing result of the Parylene coated sample. Fig. 7(a) shows the results. Both the comb and plate devices are nicely preserved. The free standing structures still remain in place with a clean dicing line in their middle. For the comb drive shaped device, the combs adjacent to the dicing line are not affected at all by the dicing wheel, whereas the plate device also is unaffected, which is a good indication of the protection capability of our technique against the harsh dicing treatment. Fig. 7(b) shows a SEM view of a Parylene coated plate device being diced through. Since the Parylene layer is relatively thin, the saw dicing on the Parylene coated sample is quite smooth. With the Parylene protection, the destruction caused by the dicing is clearly limited within the saw trace.

Besides this aggressive destructive tests, a regular dicing test is conducted as well. The dicing line is now alligned with the scribeline between of the devices, instead of through the devices. The goal of this test is to mimic the dicing condition of any MEMS sample using our Parylene temporary packaging technique. Fig. 8(a) shows an optical view of the Parylene protected sample dicing experiment. No destruction can be observed, and debris is much less this time than without Parylene coating. The reason is that during the saw dicing, Parylene functions also as a collector of the debris. Even though some dicing debris still exists, an easy rinse can solve the problem without affecting the device. This rinse condition 
a

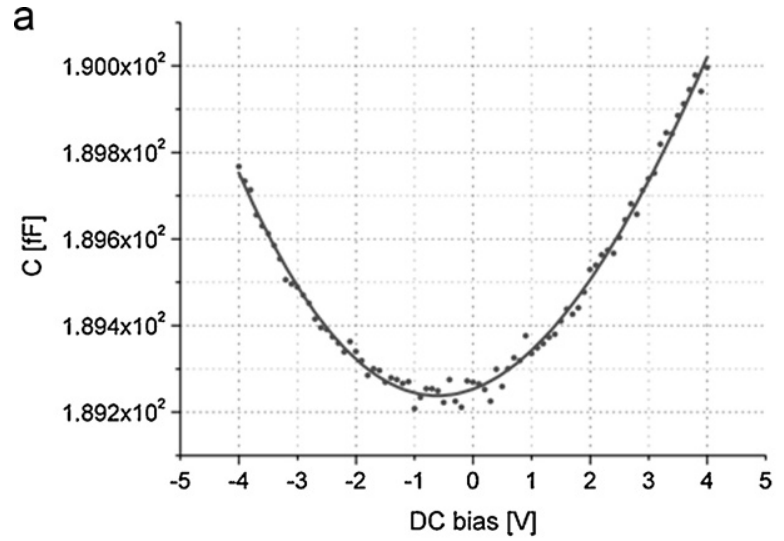

b

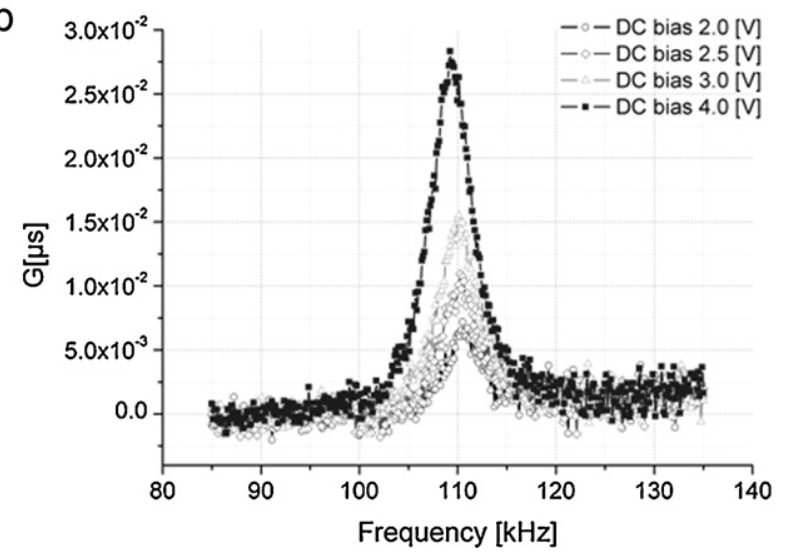

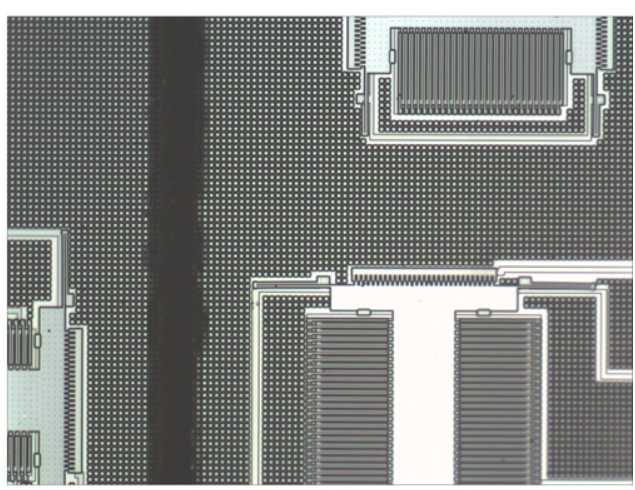

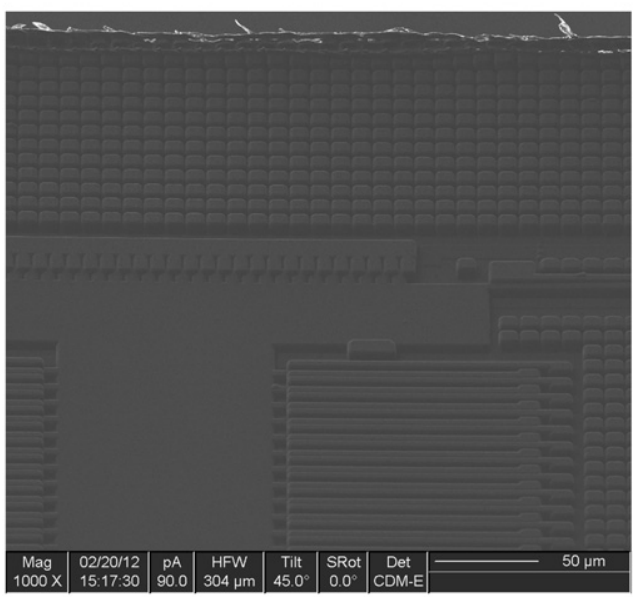

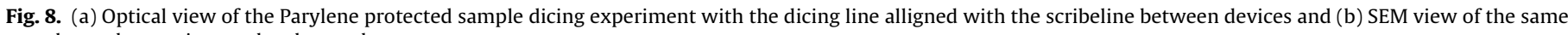
sample, no destruction can be observed.

has been proven by the ultrasonic bath test. Fig. 8(b) shows a SEM view of the comb drive device with the dicing line just visible at the top. The combs on the device are nicely protected by the Parylene coating. If the Parylene layer can be clearly removed afterwards, the device should function properly.

\subsection{Parylene removal}

Both the ultrasonic bath and the dicing tests have illustrated the protective capability of this Parylene coating technique. The temporary package can withstand the turbulence generated by the ultrasonic water bath, as well as protect the MEM structures during the dicing process. For a temporary packaging technique, the next important step is the removal of the packaging material. The main concerns for this removal step are simplicity, avoiding debris, and the ability for batch process. The removal process should not involve any wet etching process, since it will introduce capillary forces and, hence decrease the yield of the process. The removal process should work isotropically. It should be able to remove the Parylene beneath the structures as well as from the side walls and top surfaces. In order to fulfill these requirements, oxygen plasma etching (or ashing) technique is chosen. The Plasma Technology 80 series tool is used for this purpose. The etching of the Parylene $C$ samples is conducted first, with the following parameters: $100 \mathrm{~W}$ RF power, $100 \mathrm{mtorr}$ pressure, $30 \mathrm{sccm}$ oxygen flow, sample temperature $40^{\circ} \mathrm{C}$, and $4 \mathrm{~h}$ of etching.

Fig. 9(a) shows the dummy islands emerging out of the partial etched Parylene coating during the removal process. Fig. 9(b) and (c) shows some of the Parylene $C$ coated device features after the oxygen plasma ashing step. These SEM pictures reveal that some contaminations are still observed after stripping Parylene $\mathrm{C}$ with the oxygen plasma. The possible reason for the contamination is suspected to be the reaction products of the active chlorine group present per repeat unit with the polymer and oxygen under plasma condition [31].

On the contrary, the etching results of Parylene N coated samples turn out to be contamination free. Fig. 10 shows the SEM view of the sensing fingers and dummy islands, after the total oxygen plasma release of the Parylene N. Without the influential chlorine group per unit on the Parylene chain, the sensing fingers and suspension springs are released effectively. An inconvenience is still the rather long releasing time. Due to the relative large proof mass surface $(380 \mu \mathrm{m} \times 100 \mu \mathrm{m})$ versus small free-standing gap $(3 \mu \mathrm{m})$, the aspect ratio of the free-standing gap is high. Such gaps exponentially increase the release time. This should be considered during the design phase, and large areas should be avoided, since they hamper the plasma etch underneath.

\section{Electrostatic tests and discussion}

The purpose of this test is to prove the functionality of devices submitted to the temporary Parylene packaging technique. The deposition experiments have shown that both Parylene N and Parylene $C$ can be deposited on all the open surfaces of the test device. With the Parylene deposition, the coated devices with both Parylene materials can withstand the harsh treatment produced by an ultrasonic water bath. The Parylene removal experiment results suggest that the Parylene $\mathrm{N}$ is a better candidate for the temporary packaging application, since after removal no contaminations appear under the SEM observation. However, this should go hand 

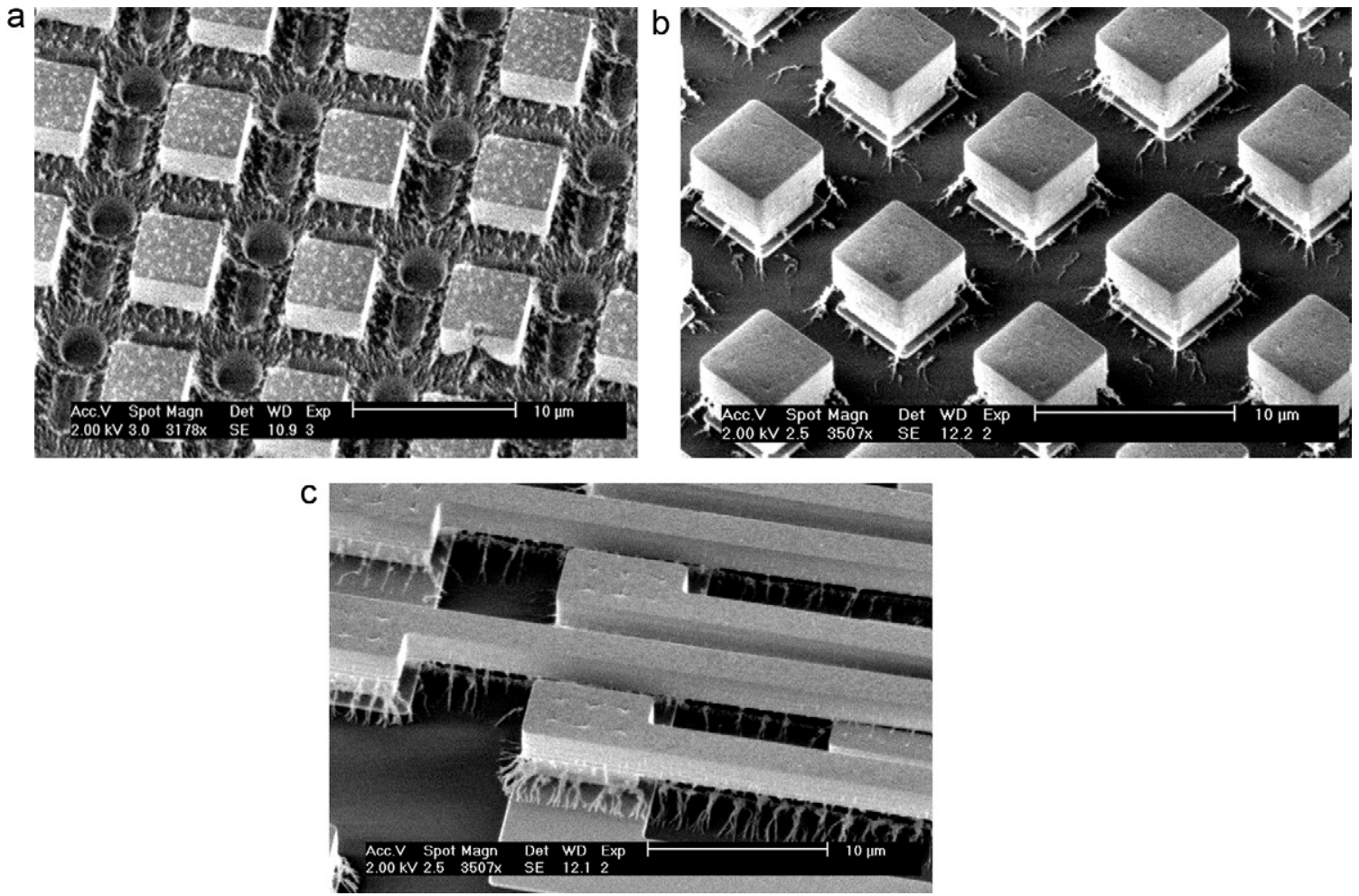

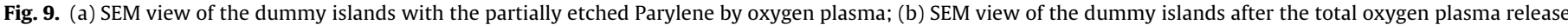
of the Parylene C coating; (c) SEM view of the sensing fingers after the total oxygen plasma release of the Parylene $C$ coating.
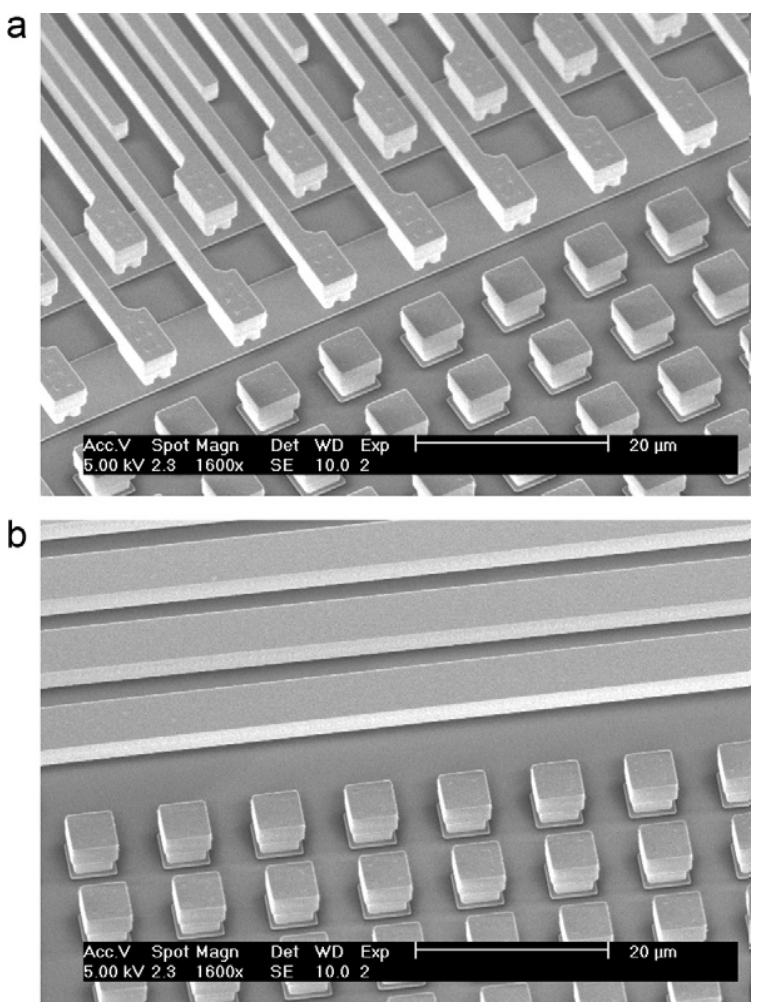

Fig. 10. (a) SEM view of the sensing fingers and dummy islands after the total oxygen plasma release of the Parylene $\mathrm{N}$ coating and (b) close-up SEM view of the sensing fingers and dummy islands after the total oxygen plasma release of the Parylene $\mathrm{N}$ coating. in hand with a careful MEMS design, since high aspect ratio gaps beneath structures take a relatively long etching time. For this reason part of our test devices could not be debonded in a reasonable time. The problem can easily be avoided by adapting the design rules for any further run. All the (narrow) comb fingers, however, are released so, to demonstrate the concept. The purpose of the electrostatic test is to check if the comb fingers respond to the applied DC and AC actuation. Since the devices coated with Parylene $\mathrm{N}$ appear clean after removal, they are submitted to this electrostatic test. The electrostatic tests are conducted using a HP 4195a network/spectrum analyzer and a probe station. One probe is connected to all the moving fingers on the proof mass, via the suspension spring and proof mass itself. Another needle is connected to one group of the differential stationary fingers on one side of the rotor fingers. If the release is successful, a DC voltage applied across these two bond pads will cause the stationary fingers to bend towards each other due to the electrostatic force, increasing the capacitance.

A $C-V$ test and additionally a resonance frequency test have been performed to the released Parylene N coated devices. Fig. 11(a) and (b) shows the results of the electric characterization of the device after stripping the Parylene $\mathrm{N}$ packaging material.

Fig. 11(a) is the test result of the test device actuated by a DC voltage sweep from $-4 \mathrm{~V}$ to $4 \mathrm{~V}$. The results indicate that the sensing fingers of the device respond correctly with the DC actuation, the testing curve is symmetric around $0 \mathrm{~V}$ with a small offset. The offset might be caused by the charging effect of the proof mass and the stationary fingers. Fig. 11(b) shows the device's frequency response to a small AC oscillation added to a DC bias voltage. The principle of the test is to use the DC bias to attract the counter electrodes of the test device, then it will respond more sensitively to the small AC oscillation single apply on the DC bias. The results show that the test device has a resonance frequency around $110 \mathrm{kHz}$, which decreases with an increasing bias voltage. 
(a)
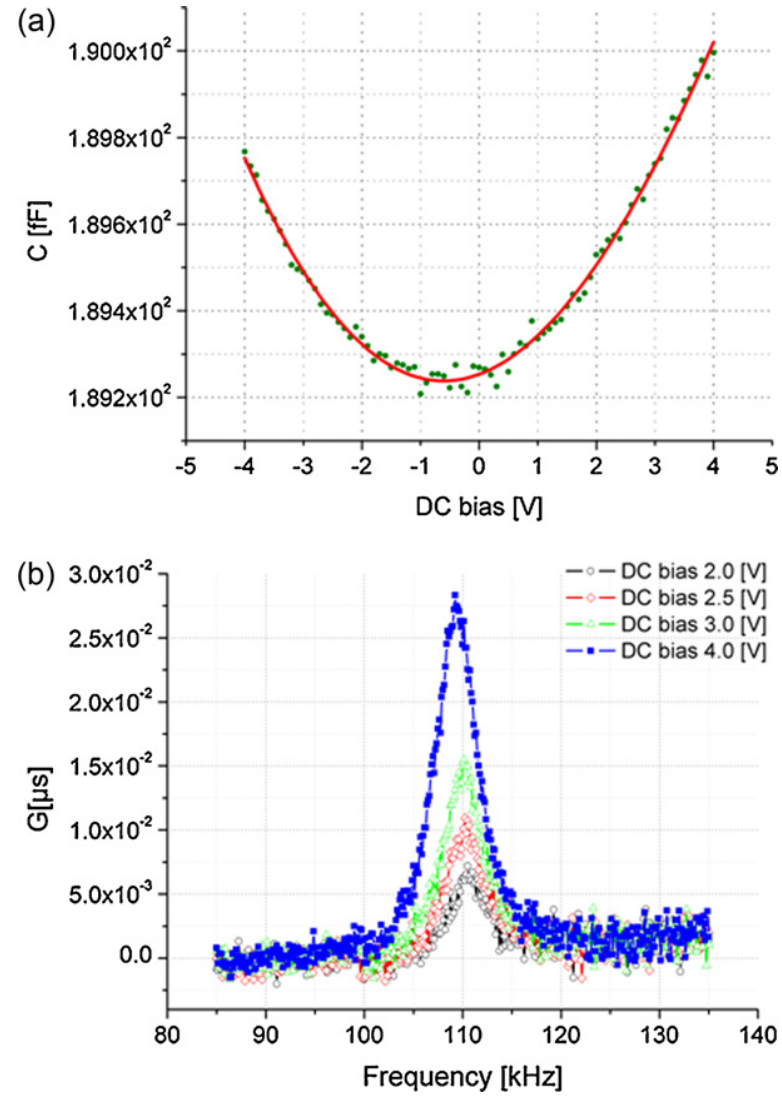

Fig. 11. (a) Electrostatic characterization after temporary packaging and release, using a DC voltage sweep from $-4 \mathrm{~V}$ to $4 \mathrm{~V}$ and (b) conductance plot measured after the removal of the temporary Parylene packaging, to determine the resonance frequency.

A FEA model is built to interpret the test result. The model is built in COMSOL 4.2. Two rectangular beams are both anchored at one end and the other ends are set to be free. The electrostatic forces are applied on the facing surfaces of the beams. The mechanical and electrostatic physics are coupled in this model. The DC bias voltage is applied from $1 \mathrm{~V}$ to $5 \mathrm{~V}$ on one beam. With that bias voltage, the resonance frequency is simulated, to verify if a similar frequency decrease can be obtained. Fig. 12 shows the simulated model (Fig. 12(a)) and the resonance frequency dropping curve with increasing DC bias, Fig. 12(b). Two situations have been simulated. In the first situation, one beam is fixed while the other beam is set free to oscillate. In this case, a clear resonance frequency drop can be observed (upper curve). The lower curve shows the two beam bending situation. The frequency drop in this curve is more dramatic than in the first case as expected.

The test results and the simulation results prove that the free standing fingers of the test device respond simultaneously with the electrostatic actuation, after the removal of the Parylene temporary package. Actually, the etching of Parylene sidewalls with oxygen plasma is not completely isotropic; in fact it is slight anisotropic. In the design phase, large contact pads or proof masses should be avoided; otherwise the residue mass stuck underneath will change the response property of the device. Since the etching time is also determined by the aspect ratio of the under-etch cavity beneath the MEMS structure, a smaller under-etch surface is recommended for designers who want to use this technique. It will greatly reduce the release time of the Parylene. On the other hand, because the thickness of the Parylene coating layer is determined mainly by the time duration when the sample (a)
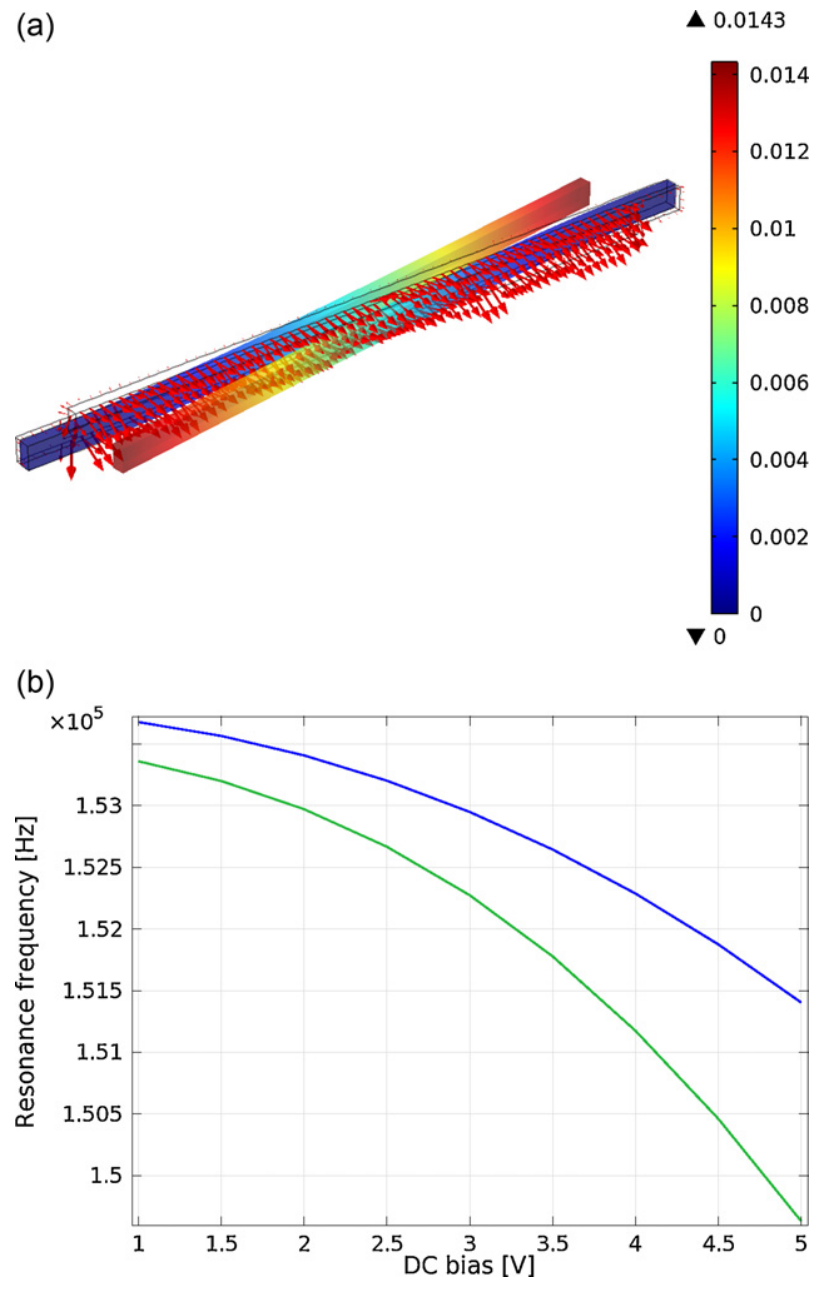

Fig. 12. (a) The FEA model of one sensing beam unit bending towards each other with $4 \mathrm{~V}$ DC bias voltage, the visual displacements are exaggerated with the factor of 800 [displacement $\mu \mathrm{m}$ ]. (b) The resonance frequency dropping curve with increasing DC bias, the upper curve shows one beam bending and the lower curve shows two beam bending situation.

temperature is lower than the polymerization threshold temperature during the CVD process. A system with direct sample temperature control can be foreseen if precise surface coverage is needed.

\section{Conclusions}

This paper presents a novel temporary packaging method for MEMS devices, by using Parylene deposition and an oxygen plasma release process. This temporary packaging method can be used for a variety of MEMS devices. Since the process has a low thermal budget, it is also suitable for CMOS compatible MEMS structures. A SiGe capacitive inertial sensor is used here as a demonstration device. Two kinds of Parylene coating have been tested. The device experienced a $10 \mathrm{~min}$ ultrasonic water bath treatment, protected by a temporary Parylene coating and survived. In terms of clean release, Parylene $\mathrm{N}$ is superior to Parylene $\mathrm{C}$. Both the $C-V$ curve and the resonance frequency test indicate that the sensing fingers of the device survived the harsh ultrasonic treatment and respond properly after the oxygen plasma strip. Hence, this work proves the feasibility of adopting the Parylene technique as a temporary protective encapsulation against harsh handling for most waferlevel released MEMS structures. 


\section{Acknowledgements}

This work has been carried out in the frame of SBO-program project 060046 , Gemini, sponsored by the 'Instituut voor de aanmoediging van Innovatie door Wetenschap en Technologie in Vlaanderen' (IWT), Belgium. This work is also supported by the Hercules initiative for Large Equipment (AKUL034, Cluster for micro and nanolithography). Frederik Ceyssens is a postdoctoral research fellow of the FWO.

\section{References}

[1] M. Esashi, Wafer level packaging of MEMS, Journal of Micromechanics and Microengineering 18 (2008) 073001, 13 pp.

[2] K. Najafi, T.J. Harpster, H. Kim, J.S. Mitchell, W.C. Welch, in: Y.B. Gianchandani, O. Tabata, H. Zappe (Eds.), Wafer Bonding Comprehensive Microsystems, vol. 1, Elsevier, Amsterdam, 2007, pp. 235-270.

[3] L.M. Roylance, J.B. Angell, A batch-fabricated silicon accelerometer, IEEE Transactions on Electron Devices ED-26 (1979) 1911-19117.

[4] A. Witvrouw, et al., Processing of MEMS Gyroscope on Top of CMOS ICs, ISSCC, 2005, pp. 88-89.

[5] J.M. Schmitt, F.G. Mihm, J.D. Mindle, New methods for whole blood oximetry, Annals of Biomedical Engineering 14 (1986) 35-52.

[6] L. Bowman, J.M. Schmitt, J.D. Meindlem, Electrical contacts to implantable integrated sensors by $\mathrm{CO}_{2}$ laser-drilled vias through glass, in: C.D. Fung, P.W. Cheung, W.H. Ko, D.G. Fleming (Eds.), Micromachining and Micropackaging of Transducers, Elsevier, Amsterdam, 1985, pp. 79-84.

[7] M. Esashi, Y. Matsumoto, S. Shoji, Absolute pressure sensors by air-tight electrical feedthrough structure, Sensors and Actuators A 21-23 (1990) 1048-1052.

[8] K.N. Chen, S.H. Lee, P.S. Andry, C.K. Tsang, A.W. Topol, Y.M. Lin, J.Q. Lu, A.M Young, M. Ieong, W. Haensch, Structure, design and process control for $\mathrm{Cu}$ bonded interconnects in 3D integrated circuits, in: IEDM Tech. Dig., San Francisco, CA, USA, 2006, pp. 367-370.

[9] H. Okada, T. Itoh, J. Fromel, T. Gessner, T. Suga, Room temperature vacuum sealing using surface activated bonding with Au thin films, in: Dig. of Tech. Papers Transducers '05, Seoul, Korea, 2005, pp. 932-935.

[10] S.N. Farrens, J.R. Dekker, J.K. Smith, B.E. Roberds, Chemical free room temperature wafer to wafer direct bonding, Journal of the Electrochemical Society 142 (1995) 3949-3955.

[11] Y. Takegawa, T. Baba, T. Okudo, Y. Suzuki, Wafer-level packaging for microelectro-mechanical systems using surface activated bonding, Japan, Journal of Applied Physics 46 (2007) 2768-2770.

[12] M. Ogihara, et al., LED array integrated with Si driving circuits for LED printer printhead, Electronics Letters 42 (2006) 881-882.

[13] M. Honma, K. Minami, M. Esashi, Face-down bonding with sealed cavity for micromechanical device packaging, Sensors and Materials 8 (1996) 23-31.

[14] H. Kim, K. Najafi, Characterization of low temperature wafer bonding using thin-film Parylene, Journal of Microelectromechanical Systems 14 (2005) 1347-1355.

[15] T. Yuki, J.H. Kuypers, S. Tanaka, M. Esashi, Capacitive RF switch fabricated by low-temperature surface process and packaged using dry film resist, in: Proc. 24th Sensors Symp., Tokyo, Japan, 2007, pp. 37-40.

[16] N. Sato, H. Ishii, S. Shigematsu, H. Morimura, K. Kudou, M. Yano, K. Machida, STP sealing technique for surface micromachined MEMS stacked on a CMOS LSI, in: Extended Abstracts of the 2002 Int. Conf. on Solid State Devices and Materials, Nagoya, Japan, 2002, pp. 320-321.

[17] K. Machida, H. Kyuragi, H. Akiya, K. Imai, A. Tounai, N. Nakashima, Novel global planarization technology for interlayer dielectrics using spin on glass film transfer and hot pressing, Journal of Vacuum Science \& Technology B 16 (1998) 1093-1097.

[18] M.W. Judy, Evolution of integrated inertial MEMS technology, in: Solid-State Sensors Actuator and Microsystems Workshop, Hilton Head, SC, USA, 2004, pp. 27-32.

[19] Y.T. Chang, W.T. Hsu, K. Najafi, C.T. Nguyen, Vacuum packaging technology using localized aluminum/silicon-to-glass bonding, Journal of Microelectromechanical Systems 11 (2002) 556-565.

[20] M. Chiao, L. Lin, Hermetic wafer bonding based on rapid thermal processing, Sensors and Actuators A 91 (2001) 398-402.

[21] L. Wen, B. Guo, L. Haspeslagh, S. Severi, A. Witvrouw, R. Puers, Thin film encapsulated SiGe accelerometer for MEMS above IC integration, in: Proceedings of The 16th International Conference on Solid-State Sensors, Actuators and Microsystems, Beijing, 2011.
[22] Europractice website: http://www.europractice-ic.com/wordpress_LF/wpcontent/uploads/2011/05/2.Ann-Witvrouw.pdf.

[23] L. Wen, K. Wouters, R. Puers, SU-8 thermo-compressive packaging for postCMOS poly-SiGe MEMS, in: Proceedings of Eurosensors XXIII, Lausanne, Switzerland, 2009.

[24] A. Witvrouw, et al., Packaging of 11Mpixel CMOS-integrated SiGe micro-mirror arrays, in: Proc. IEEE MEMS, 2009, pp. 136-139.

[25] L. Bogaerts, Temporary 0-level MEMS packaging using a heart decomposable sealing ring, in: Proceedings of Eurosensors XXV, Athens, Greece, 2011.

[26] Y. Li, D.W. Hess, Plasma etching of thick polynorbornene layers for electronic packaging applications, Journal of Vacuum Science \& Technology B: Microelectronics and Nanometer Structures 20 (5) (2002) 2007-2012.

[27] J.B. Fortin, T.M. Lu, Mass spectrometry study during the vapor deposition of poly-para-exlylene thin films, Journal of Vacuum Science \& Technology A18 (2000) 2495, 7 pp.

[28] P. Kramer, A.K. Sharma, E.E. Hennecke, H. Yasuda, Polymerization of paraxylylene derivatives (Parylene polymerization). I. Deposition kinetics for Parylene N and Parylene C, Journal of Polymer Science: Polymer Chemistry Edition 22 (2) (2003) 475-491.

[29] Scscoating website: http://www.scscookson.com/Parylene/properties.cfm.

[30] J. Van Borkulo, R. Evertsen, R. Hendriks, Enabling Technology in Thin Wafer Dicing, ALSI, platinawerf 20G, 6641TL Beuningen Netherlands, 2009.

[31] E. Meng, P.Y. Li, Y.C. Tai, Plasma removal of Parylene C, Journal of Micromechanics and Microengineering 18 (2008) 045004, 13 pp.

\section{Biographies}

Lianggong Wen was born in Harbin, China. He received the M.S. in electrical engineering from the Katholieke Universiteit Leuven, Belgium in 2007. He is now working as a research assistant at ESAT-MICAS of K.U. Leuven. His research interests are polymer inertial sensors, SiGe MEMS above IC sensors, and MEMS packaging.

Kristof Wouters was born in Aarschot, Belgium in 1983. He received his master of engineering degree in 2006 . He is now working as a research assistant under prof. Puers. His main research interests are the investigation of the use of polymers as a structural layer in MEMS.

Frederik Ceyssens was born in Sint-Truiden, Belgium, in 1980. In 2003 he received the degree of M.S. in electrical engineering from the Katholieke Universiteit Leuven, Belgium. After that, he became research assistant at MICAS, investigating novel microfabrication (MEMS) technologies such as SU-8 and their applications in integrated optics and sensors. In 2009, he obtained the Ph.D. degree. He is currently working as a research fellow of the FWO, researching novel brain-computer interfaces in a collaboration between K.U. Leuven and the Gasthuisberg university hospital.

Ann Witvrouw received an M.S. degree in metallurgical engineering in 1986 from the Katholieke Universiteit Leuven, Belgium, and both an M.S. degree in applied physics in 1987 and a Ph.D. degree in applied physics in 1992 from Harvard University, USA. Since 1992 she joined imec, Belgium where she worked on the reliability of metal interconnects until the end of 1998. In 1998 she switched to research in micro-electromechanical systems at imec, focusing on advanced MEMS process technologies. Since 2000 she is working on MEMS integration, first as team leader, then as a program manager and currently as a principal scientist.

Robert Puers obtained his Ph.D. at the Katholieke Universiteit Leuven, in 1986 The same year, he became director of the clean room facilities for silicon and hybrid circuit technology at the ESAT-MICAS laboratories at the K.U. Leuven. He was a pioneer in the European research efforts in silicon micromachined sensors, MEMS and packaging techniques, for biomedical implantable systems as well as for industrial devices. In addition, his general interest in low power telemetry systems, with the emphasis on intelligent interface circuits and on inductive power and communication links has promoted the research of the ESAT-MICAS laboratory to international recognition. At present, he is as a full professor at the K.U. Leuven, teaching courses in 'Microsystems and Sensors', 'Biomedical Instrumentation and Stimulation', 'Biomedical Equipment and Regulations', 'Production Techniques for Microelectronics', and basic courses in 'Electronics, System Control and Information Technology'. He is co-author of more than 550 papers on biotelemetry, sensors, MEMS and packaging in reviewed journals or international conferences. He is a fellow of the IEEE and of the Institute of Physics (UK), member of the Electron Device Society (EDS) and many others. 